\title{
The impact of physics on society and the mission of physics education in secondary schools
}

Etienne De Wolf*

\section{The impact of physics on society}

\section{Science is culture}

$T^{n}$ the last decades, scientific knowledge and technology have $I$ grown at a spectacular rate, and had a dramatic impact on society. Our society in Western Europe now even has become very dependent on technology: for its housing, heating, lighting, clothing, food, mobility, health care, safety and security. Without technology, most of our durable goods, public utilities, consumables and services would simply not exist. And physics is one of the most important sciences that are responsible for these developments.

But the impact of science would not have been possible without the contribution of other factors, which finally determine whether or not a scientific discovery will have an influence on society at all, and if it does, what kind of influence this will be. There is a long and complex way to go between a new scientific discovery and its effects on society.

Most citizens will only become aware of such discovery when it concerns a spectacular new scientific insight and if, on top of that, the media decide to bring it to the people's attention. And then in most cases they rightly will be told at the same time that it may take many years before we can expect any practical application of this discovery. But it is precisely these practical applications that have an impact on society.

If, for some reason, a scientific discovery is not used for new technology, then only a very limited group of citizens will be affected by it. Namely just those who cared to inform themselves, and who were lucky to have had a scientific education that enables them to understand what exactly this new discovery is all about. These few privileged people will probably be charmed once more by the beauty of nature or by the elegance of the new scientific theory.
So, even if there are no practical applications, scientific discovery still is a cultural enrichment for society. Therefore science is one aspect of culture. And it would be worth while to make this aspect of culture accessible to more people. That is possible, if we are prepared to invest in "professional vulgarization". Vulgarization is, in the first place, a task for scientists themselves, who should not consider this to be incompatible with their dignity. However, it also belongs to the mission of schools, cultural organizations and the media. Fortunately, every once in a while we see beautiful examples of serious vulgarization. But with all the spare time we now have available, and with all didactical means we now have at our disposal, there is certainly room for more. Good vulgarization of science has a positive impact on society.

Nevertheless, scientific discoveries only have a substantial impact on society if they ultimately lead to attractive new or improved products, with which we will deal in our day to day lives. And for this conversion of science into products, we need technology.

\section{Science and technology}

Science has to do with knowing, technology has to do with acting. Science comprises every thing mankind knows about matter, energy, natural forces and laws of nature, and about the natural phenomena as they present themselves in the universe.

A scientist builds his knowledge on attentive observation, measurement, systematic analysis and carefully designed experiments. Starting from his own observations and those of his colleagues worldwide, a scientist constructs models and mathematical formulas, which bundle these observations into a coherent theory. His work is an effort to discover, identify and formulate the laws of nature. These laws describe the structure of 
matter, and the relationships between cause and effect. Science enables us to understand what is going on in nature, and to predict what is going to happen under what circumstances. The validity of such predictions is then tested in new experiments. And as soon as a theory is contradicted by one single new fact, it will be revised or refined. By systematically and consistently following this procedure, natural sciences have achieved spectacular new insights in how nature works.

Technology is something completely different. In science, we discover things, in technology, we make things. Technology is a body of methods, procedures and tools, invented by man, starting from what science has discovered in nature.

The purpose of science is "to understand, to explain and to predict". The purpose of technology is "to change the world", to bend things and situations towards goals that match the interests of those who control technology, and who dispose of the means to make things happen.

\section{Economic thinking as the driving force}

As soon as somebody has identified an attractive application of a new scientific discovery, economic thinking comes into the picture. And this is the third step in the chain: science, technology and economy. Scientific knowledge is a necessary condition for technology, but is not sufficient. The driving force for technology stems from economic thinking.

The purpose of economic thinking is to create maximal practical utility or pleasure with minimal efforts and means. The creation of useful and pleasant things on one hand, and economical use of means on the other hand, are fundamentally two valuable goals. Nowadays economic thinking is common practice in society. It is a basic tool for all industrial and commercial companies, as well as for non-profit organizations and public authorities. But because of this way of thinking, companies, organizations and authorities will exclusively invest in the development and exploitation of those technologies, for which the perceived "advantages" are greater than the required "offers".

The offers consist of time and money to be spent on product development, on the development of manufacturing techniques, on investments, raw materials, labor and advertising. Advantages and offers will be weighed against each other, and in order to make them comparable, both will be expressed in financial terms. If, on the long term, revenues do not outweigh cost, then companies will not engage in the project.

Companies are "communities of shared interest", with 5 participants: customers, personnel, shareholders, suppliers and society. Each of these participants contributes to the businessprocess in his own specific manner. Each participant engages to do so because he understands that he can only attain his own targets by cooperating with the other participants. So, companies fulfil a social-economic role in society. Companies create products and services for their customers, income for their personnel and for their suppliers, and a financial compensation for the money their shareholders put at risk. Companies also pay taxes, which generate means for the financing of public utilities and services.

In order to fulfill this multiple function, companies must also make a profit. Contrary to what some people think, profit is not a "redundant surplus". Making a profit is not a crime. It is a duty! Corporate taxes as well as dividends for the shareholders can only be paid out of the pot of what legally is defined as "profit before taxes". Furthermore companies also have to keep part of their profit within the company, in order to safeguard their future existence. Indeed, retained profit must serve to finance growth, to finance adaptation to technological progress, and must serve as a buffer against bad times. Without profit, a company will not be able to fulfill its social role in the future. It will not be capable to continue to reward its shareholders, nor to deliver competitive products, nor to supply jobs. Profitability is a social obligation of a company, in the interest of all participants in this "community of interest", and thus in the interest of society.

Therefore companies will focus their means on activities that yield more than they cost. The principle of economic thinking substantially determines which applications of science will be technologically exploited and become visible in society. Economic thinking is the driving force for the impact of science on society.

\section{Market-economy}

In a market-economy, the "economic value" of a new product, as well as its cost, are both determined by the mechanism of supply and demand. These two factors determine what quantities will be sold and bought, and at what price.

Supply and demand both result from the interaction between technical possibilities on one hand, and a combined play of sociological and demographic factors on the other side. Supply and demand depends on what citizens perceive as attractive. And this in turn depends on their social status, their education, their age and their moral values. It also depends on the alternatives from which they can choose, on what their idols do and wear, and on what people see and hear in advertising. The structure of the market, the perceived attractiveness of products to potential buyers, and the outlook on profitability for manufacturers, are the factors that will determine which applications of science will effectively have an impact on society.

\section{Competition sets the standards}

Another important factor in market economy is competition. Competition continuously raises the standards for technological realizations. Competition forces companies towards ever better performance. The best performing company automatically becomes the point of reference for all others. Consumers do compare and choose without compassion. If other suppliers do not succeed to match or exceed the performance of the smartest competitor, these companies will not survive. Consequently, standards of "quality for money" will be raised step by step. Thanks to competition society gets more value out of scientific discoveries. And that of course is good. We now can buy a pocket-radio that is a hundred times smaller than a radio 50 years ago, which produces a much better sound and has more functionality, at a price that is only a fraction of what it was before.

Absence of competition stops technological research. Just look at what happened in Eastern Europe before 1989. They had a "guided economy", where national authorities decided what should be developed, what and how much should be produced, by whom, and at what price it had to be sold. We all know the result: people lining up for small, but scarce and expensive, toy-like cars, called "Trabants". And that was not caused by Russian ignorance of scientific discoveries. Russian physics was not different from Western physics! Their poor realizations were due to lack of competition, and that caused the collapse of their system. 
The co-ordinated actions of science, technology and marketeconomy have not only created better products at lower prices, they also have enabled us to drastically decrease our working time. In Beigium we only work 1.500 hours a year. And we hardly have to do this 40 years long. Whereas our life-expectation now exceeds 70 years. A simple calculation proves that now about $90 \%$ of our (prolonged) lifetime is available for education, for recreation, for sports, for personal care, for communicating with others, for making other people happy, for enjoying culture, and for relaxing. To a great extent, this has been made possible thanks to technological, and economically profitable, applications of physics!

\section{The flip-side of the coin}

Nevertheless it would be unfair to conclude that everything that results from "profitable applications of physics", would be a blessing for society. Market economy, just like anything else, has its limitations and its drawbacks. But that is no reason to throw it away. It's only a good reason to add an extra factor to our chain.

In my opinion the three main limitations of market economy are:

1. that producing good things, based on science and technology, may have undesired negative side-effects, which are not automatically taken care of by market mechanisms

2. that science and technology can also be used to create "profitable rubbish", "profitable crime", or even "profitable warfare", and

3. that quite a number of good things in society, and even some of the very best, can not be generated by market mechanisms (and most of them don't even require science or technology either!)

Every coin has its flip-side! We can't make omelets without breaking eggs. We can't technologically manipulate nature without disturbing it. Technology implies extraction and consumption of raw materials. It consumes energy and produces waste. As long as the negative side-effects the disadvantages are minimal, we readily will accept them, and live with it. But on "space-ship earth", the home of society, we must survive with what we have aboard, and with anything that reaches us from outer space. This is an inevitable fact, with which we have to cope. If, in applying science, we exhaust irreplaceable resources, or produce more garbage than our space-ship can take, then we are putting society at risk.

In fact, the disadvantages of our technological actions should be taken into account in our economic calculations. However, some of these escape from such calculations. Think of disadvantages that are suffered by third parties, which even don't enjoy any of the positive effects. Likely victims are the biosphere, weaker segments of society, or future generations. As long as these negative effects can not be charged as a cost to those who cause the disadvantages, they will not figure in the calculations.

\section{Corrective measures}

Negative side effects that can not be eliminated by market economics, can be mastered by "corrective measures". Doing this, adds an additional step to the chain that links science to society.
Whether science will have an impact on society at all, and what this impact will be, now already depends on four factors: scientific discovery, technology, economic thinking and corrective measures.

As far as corrective measures is concerned, a series of considerations have to be made:

1. Corrective measures can be self-imposed by an individual company or a group of companies, as a sign of "responsible citizenship". But in most cases they are imposed by a central authority, or in a democratic way, as is the case in Western Europe. There is however a problem with democratic decision making for such complex matters as technologic or scientific progress. It is indeed quite unlikely that all participating citizens and their representatives are technically capable to make a fair balance between the pro's and con's, and to judge which of the proposed rules are wise and which are not.

2. All corrective measures have their price. Rules, by definition, limit our freedom. So, if society wants to prevent certain negative effects, it will have to renounce the attractive side of what is being forbidden. We must have the courage to choose.

3. As globalization is penetrating society, we cannot afford to maintain stringent measures here, when other parts of the world compete with us without caring about the negative effects. Therefore globalization of business requires a corresponding, adequate globalization of social and ecological correcting measures. In this area I think a lot of work is still to be done.

4. Some negative effects will escape from all measures, as they concern drawbacks, which are unknown by mankind in the present state of our scientific knowledge. The most striking consideration in this respect is that, in a way, every thing depends on everything, that we are citizens of the universe, and that this cosmos is far too complex to ever be completely understood by man. This means that we can not oversee all the consequences of our acts. And that should motivate us to practice a certain degree of modesty. Science is not omniscient. Therefore in case of doubt we should refrain from action. In fact, this could be proclaimed to be a "rule of the game" too. Wouldn't that be wise?

5. Not everything that is technologically possible and economically profitable is automatically compatible with our ethical standards. Ethics does not result from scientific research, or from technology, or from economic thinking, or from democratic decision-making. Some possible applications of science are bluntly crimes. But others are considered to be acceptable practice by some people, but are unacceptable to others. And this calls for another step in the chain. I'll come back on this below.

6. The only way to achieve a situation where society can fully enjoy the positive effects of technological progress, without having to accept all the negative side-effects, is to continue scientific research, so that we can develop new, improved technologies, which eliminate the major drawbacks.

\section{Individual responsibility}

Scientific discovery, technology, economic thinking and corrective measures are four elements, which, together, determine the impact of science on society.

But there is still another factor that deserves more attention and which, in my opinion, may well become the most important one. Apart from natural phenomena, all changes in society result from actions of man. People are the ultimate driving force behind all factors that have an impact on society. Science obviously is the basis for all technology. Market-economy clearly 
constitutes the most efficient way to produce welfare at minimum cost. Democratic decision-making appears to be the safest way to reduce undesirable negative effects, and to safeguard our social and ecological values.

However, "what the market demands and offers", or "what the political majority decides" is always the result of decisions of many individuals. In this complex process every citizen must be aware of his or her co-responsibility. As an individual citizen you are not left without power, at least if you join forces with others.

But even if your position is not shared by anyone else, then, as an individual, you still have quite some latitude to do what you really want to do. It is not because it is trendy to buy a product, that we have to buy it. It is not because democratically voted rules do not forbid certain actions, that we are obliged to commit them. Ultimately you can, within certain limits, decide and live according to your own principles. As long as you don't violate the very few basic principles of human dignity. In most cases there is really no excuse to hide behind rules, if these are in conflict with our conscience.

And that completes the chain of factors that link science to society. Scientific discovery, technological applications, economic thinking, corrective measures and individual responsibility are the 5 cornerstones of any progress in society.

This brings me to my second theme:

\section{The mission of physics education in secondary schools}

\section{Do you really need physics?}

Allow me to be nasty for a while, and to boldly ask the question whether we need physics education in secondary schools at all? Do you really need physics to become a good factory worker? Or a good bookkeeper, or an efficient salesperson, or a good busdriver? Do you need to understand the laws of Ohm and Kirchoff in order to be able to push the button to switch on the light? Will you be a better communicator in using your GSM when you understand the laws of electromagnetism? Will you do better cooking if you know how microwaves work? Do people feel they are better citizens or better parents because they had lectures in physics in secondary school? My guess is that very few citizens would answer these questions by a definite "yes". A minority would probably answer that "it was not really necessary, but that nevertheless it was nice". Whereas the majority would bluntly say "no" without any scruples!

Are we then wasting our time on something, which is perceived as redundant for most people in society?

Of course if you want to become a technician, specialized in electricity, and if secondary school is the final level of your formal education, then you will want physics classes that inform you on electricity. Indeed, as an electro-technician you must be able to solve practical problems in an electrical circuit or machine. And then it is useful to understand what you are doing. In this case physics teaching in secondary school is an element of your professional training, and your employer will most certainly want to see your diploma. Although it is very likely that he will give you some dedicated training for repairing his specific products. You will probably even receive a handy manual, containing all the steps you blindly have to go through in order to detect the defect and to solve it by simply replacing the defect component, not by repairing it! So even in this case you could ultimately argue that secondary school should better replace physics teaching by a training in correct reading and using manuals!

Maybe I'm exaggerating. Let's say that we all agree that the future electro-technician does need physics teaching in secondary school. But wouldn't it be sufficient to have physics in technically oriented school-programs, and only in those? Is there any good reason to insist on physics teaching in the other orientations of secondary schools?

\section{Education}

The answer of course is clear: schools must provide for education; but education is more than just the transfer of know-how and skills that are focused on immediate practical utility.

The purpose of education is "to prepare young people to become responsible citizens".

In order to deserve the qualification "responsible", a citizen must be able

1. to cope with the world

2. to develop his personality

3. to contribute to the future and

4. to balance conflicting factors

So these are, in my opinion, 4 elements on which education must focus.

Let's take a closer look at each of them.

"Coping with the world" means

- that you know what the physical world and society have to offer

- that you know what is attainable and what not

- that you are familiar with the rules of the game of the cultural sphere in which you are raised

- that you are "willing and able" to conform to these rules, at least to the minimal extent that is required to avoid serious conflicts

- that you have acquired certain skills and attitudes, which you need to function more or less "normally" in your family, among your friends, with your neighbors, in your job, in your country, in the European Union, and aboard our "space-ship earth"

It also implies

- that you are willing and able to adapt to change

- that you can communicate and cooperate with others

- that you can enjoy the beauty of nature, accepting the unpleasant aspects of it

- and that you can respect and enjoy the technical and organizational realizations of humanity over history, accepting that the coin also has a flip-side.

"Developing your personality" means

- that you learn to identify your individual capabilities and restrictions

- that you learn to enjoy your strengths and to live with your weaknesses

- that you see set-backs and failures as challenges to learn to do better

- that you are prepared to invest in "learning to do", in "learning to learn" and in "learning to think"

- that you learn to stand up for your self

- that you learn to respect other people and their ideas

- that you learn to take initiatives and to accept that initiatives unavoidably imply risks 
- that you learn to enjoy helping other people

- that you can position yourself in society, and see your role in each of the greater systems of which you are part, whether you like it or not,

- and finally that you can find sense in your life and in what you are doing.

"To contribute to the future" is a task for each citizen, irrespective of his position. Some of our present students will become our future political leaders, professors, business-managers or unionleaders. Others will hold responsible positions in administration or in social or cultural organizations. Or will become opinionleaders, journalists, tastemakers, or militants in pressure groups. These people will be confronted with important new challenges and opportunities, about which they will have to take decisions that will affect the life of our children and grandchildren. I think their most important responsibility will be the creation of "a durable economy and a durable society". They also will have to make rules for "corrective actions" regarding

- the use of energy and raw materials

- the management of waste and

- the care for safety and security of technology and of society. Being challenged by new facts, new insights or new discoveries, they will even have to fine-tune, renegotiate or revise some of our traditional values and priorities.

But not only people in leading positions will contribute to the creation of our future. Any citizen will, to a certain extent, influence the changes in society: either as a parent and educator, or as a consumer, as a worker, as a member of social or cultural organizations, as a private investor, or ultimately as a voter.

The fourth requirement for "responsible citizenship" is "balancing conflicting factors".

Education should help young people in learning to balance

- "interests on short term" against "interests on the long term"

- "innovation" against "conservation"

- "personal interest" against "common interest"

- "the interests of the community with which we identify ourselves" against those of "differentiated communities"

- "fighting to improve things that we believe we effectively can improve" against "accepting things that we feel we really can't change"

We must also help our students in learning to balance

- "tolerance" against "looking away" or "confrontation"

- "living in harmony" against "engaging in conflict"

- "appreciating differences as an enrichment" against "striving for unity"

- and to balance "the interest of man" against "the conservation of our biosphere".

Preparing children and adolescents for adult life is an enormous responsibility, to be shared by parents, schools and social organizations. In this process secondary schools are particularly important, as they deal with youngsters in the most critical phase of their development.

\section{Physics education}

Physics education is not an item on its own. In my opinion, physics education in secondary schools should be an integrated component of the "total educational project" of the school. As we have more than one network of schools in Belgium, as education is a matter that belongs to the competence of the regions, and as most schools offer several programs with different orientations, we should not be surprised that we find a variety of "total educational projects". And to me this variety is an asset. But whatever differences there are in accents, any total educational project must be oriented on the "general mission of education", as we have tried to describe it, namely "to help young people to become responsible citizens". Accordingly, any specific subject, whether it be physics or history, must contribute to that goal. I believe that in teaching physics, just like in teaching any other subject, there are many occasions to inject one or more of the many items that we listed under the 4 factors:

- coping with the world

- developing personality

- contributing to the future and

- balancing conflicting factors.

Just picking one item here and there, I think physics teaching can - create occasions for the students to learn to communicate and cooperate with others

- invite them to respect and enjoy the scientific realizations of humanity over history

- give students a chance to identify their individual capabilities and restrictions

- challenge them to stand up for themselves and to respect other students and their ideas

- challenge them to take initiatives and to accept failures

- require that they take responsibility for their own future when they will finish school, or

- teach them to balance the interest of man against the conservation of our biosphere.

Furthermore, due to its specific subjects, physics teaching is in a unique position to make very specific contributions to general education. For instance

- by provoking astonishment, amazement and respect for the incredible beauty of matter and of the forces that reign in it

- by explaining the practical meaning of a number of physical notions with which we are confronted in our day to day life

- by familiarizing people with "neat thinking" and with the "scientific approach", including rigorous observation and experimentation, measuring the world, working with tentative assumptions, challenging assumptions and correcting them as required by new facts, and appreciating the limits of extrapolation. This methodical way of thinking and acting is not only applicable to physics, but also to a number of small or bigger private or professional projects, in which any citizen will sooner or later be engaged!

Physics teaching is also in a good position to indicate that history of science demonstrates that what we believed to be a reliable physical theory in the past, in many cases has proven to be inadequate, after we took an extra look, with better tools or under new circumstances. And physics teaching is a unique occasion to recognize that some modesty is required, as science understands only a small part of material reality, and that we can not oversee the ultimate consequences of all technical manipulations.

In conclusion, the mission of physics teaching in secondary schools is not only to convey practical skills and knowledge about the structure and behavior of matter, but also, and maybe in the first place, "to contribute to education for wisdom and responsibility".

Most certainly this can be very exciting for teachers. And for students as well. 
* Edited version of the talk delivered at the "Physics Teaching Forum", organised on March 16th, 2002 in Brussels by the National Committee for Physics of the Belgian Royal Academy of Sciences,. The author is a physicist. He held several management- and board-positions at the world-wide Agfa-Gevaert Group and is Executive Professor at the University Antwerp Management School. He is a Belgian citizen and father of a happy family with 3 grown-up children. The author emphasises that this article is not based on any systematic research on the needs for physics teaching, but merely represents his personal view.

\section{Let's talk about it}

\section{Aart W. Kleyn, Chairman, EPS Physics Education Division and Leiden University, The Netherlands}

$T^{t}$ is a very positive thing that $\mathrm{Dr}$ de Wolf, with his strong back$l$ ground in physics, business and management, expresses his views on physics education in secondary schools. More attention for physics at secondary schools is badly needed, and his initiative is very welcome. It demonstrates that physics education is appearing on more and more agendas. Dr de Wolf's systematic analysis clearly betrays his education as a physicist. I have a few thoughts on the analysis that I want to men-

tion here. For instance, it is hard to maintain that scientific discoveries only have impact on society if they lead to products. Think about the impact that Galileo had on thinking and religion. Think about the impact of quantum mechanics on philosophy and the arts. I disagree that society is exclusively the market place. Government and its agencies have a very powerful role in society. Both employ many physicists and they are not always market oriented. It is an interesting notion that globalisation will require corrective measures'. I remark that physics essentially always has been global, and therefore it needs less corrective measures and can set an example for others. In the same context, Dr. de Wolf remarks that science is not omniscient. However, science will definitely come much closer to that if it is disconnected from the acts of certain factions in society, in order to try to foresee what the consequences of science (done by others) will be. In case of doubt, we should call for more science, and in many cases not refrain from action.

More to the main topic of the article: in the discussion about physics education in high schools I miss the discussion about content in connection with the level of education. The physics that one needs depends on the type and level of the job. And education should differentiate. To implement this differentiation well is a major challenge, especially since the career path after a certain education can be so broad. The discussion on education seems to be concerned with low-level technical education. I hope Dr de Wolf does not want to turn everyone into a robot, well versed in correct reading of manuals. My former research technicians were not keen on continuing their careers into such kind of jobs, even though their formal training in physics was sometimes very limited.
I believe what has to be added to the discussion started by Dr de Wolf are questions such as: Do we attract good physics teachers with general statements, and how do we attract them? How do we introduce the concept of general laws, based upon observation and mathematical theory, rather than upon conviction, religion of political view? What is the role of experiment and careful, critical observation? How do we build equipment for such observations? How do we turn quantitative observation into a mathematical theory? What are the laws of physics that pupils need to know? What are the ingredients of physics that 'everybody' ought to know? Is it stimulating to bring new physics into the class-room? A lot of the content connected to the points mentioned above will certainly contribute to the general points made by Dr de Wolf, and they create useful skills and knowledge for the pupils.

Without such discussions on the explicit content and its implementation I am afraid that general statements such as "the purpose of education is to prepare young people to become responsible citizens" will only be used to eliminate physics from high schools. In my country this process is well under way. I thank Dr de Wolf for stimulating our thinking about physics education in general. Within the activities of the Physics Education Division we will keep his remarks in mind and hope they will stimulate further discussion on physics education, perhaps also on the pages of this Journal.

\section{The author replies}

$A^{\mathrm{n}}$ open discussion and confrontation of opinions, backed by I experience and supported by arguments, are the most reliable basis for improving our knowledge.

Furthermore I agree with Prof. Kleyn that the impact of science on society is not restricted to "products". His reference to thinking, religion, philosophy and even to arts is very to the point. I consider this comment as a valuable complement and correction to my own statements. For which I'm grateful.

Initiatives by governments and agencies based on new scientific discoveries indeed also have an impact on society, but the results of such initiatives, although not directly financed or promoted by companies, in fact can be regarded as "products" as well.

However it seems unfair to suggest that I might "want to turn everybody into a robot, well versed in correct reading of manuals". Careful reading of my text reveals that I plead for the contrary. But we should face the fact that technicians in a number of cases are "reduced" to that role.

If statements such as "the purpose of education is to prepare young people to become responsible citizens" would drive authorities to eliminate physics from high school programs, then the conclusion should not be that the purpose of education must be something else, but rather that these authorities draw the wrong conclusions. This should stimulate us to increase our efforts to convince these authorities that physics teaching can contribute substantially to the education of young people to indeed become responsible citizens! Formulating arguments for this view is the essence of the second part of my article. 